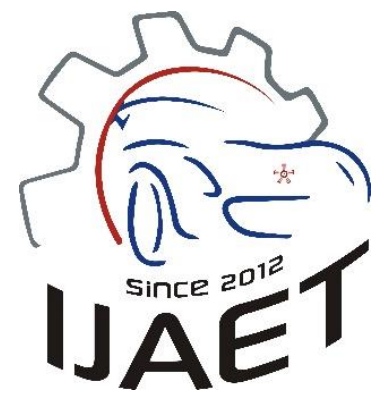

e-ISSN: 2146 - 9067

International Journal of Automotive

Engineering and Technologies

journal homepage: http:// http://dergipark.gov.tr/ijaet

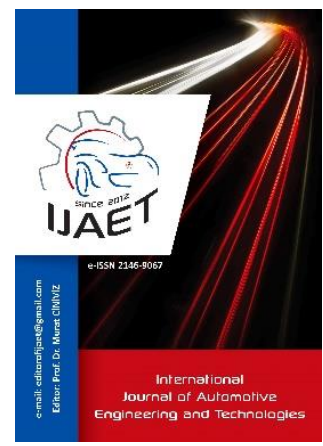

Original Research Article

\title{
Performance and emission characteristics of a miller cycle engine
}

Oğuz K. Demirci ${ }^{1}$, Ahmet Uyumaz ${ }^{2 *}$, Suat Saridemir ${ }^{3}$, Can Cinar ${ }^{4}$

${ }^{1}$ Department of Automotive Engineering, Graduate School of Natural and Applied Sciences, Gazi University, Teknikokullar Ankara, Turkey

${ }^{2}$ Automotive Technology Program, Vocational High School of Technical Sciences, Mehmet Akif Ersoy University, Burdur, Turkey

${ }^{3}$ Department of Manufacturing Engineering, Faculty of Technology, Düzce University, Duzce, Turkey

${ }^{4}$ Department of Automotive Engineering, Faculty of Technology, Gazi University, Teknikokullar Ankara, Turkey

\section{ARTICLE INFO \\ * Corresponding author auyumaz@mehmetakif.edu.tr \\ Received: February 15, 2018 Accepted: September 27, 2018}

Published by Editorial Board Members of IJAET

(C) This article is distributed by Turk Journal Park System under the CC 4.0 terms and conditions.

\begin{abstract}
In this study, intake and exhaust cams were designed to perform the late intake valve closing (LIVC) Miller cycle operation (MA and MB cycles) using spline functions in a single-cylinder, four-stroke, spark-ignition (SI) engine. A special camshaft was manufactured and adapted to the engine to adjust valve opening and closing timings. The experiments were conducted at two different Miller cycle operation and the results were compared with Otto cycle. The tests were conducted between 1700-3200 rpm engine speed range at wide open throttle (WOT). In the experiments, the variation of brake torque, power output, specific fuel consumption (SFC), thermal efficiency, $\mathrm{HC}, \mathrm{CO}, \mathrm{NO}_{\mathrm{x}}$ emissions and exhaust gas temperature versus engine speed were investigated. More power output was obtained with Otto cycle than Miller cycles for all engine speeds. Brake torque and engine power decreased by $5.24 \%$, and $1.17 \%$ respectively with MA cycle compared to Otto cycle at $2600 \mathrm{rpm}$ engine speed. Thermal efficiency increased by $1.29 \%$, while the SFC decreased $2.08 \%$ with Otto cycle in comparison with MA cycle at maximum brake torque speed. HC and $\mathrm{CO}$ emissions increased by $6.48 \%$ and $11.66 \%$, respectively with MA cycle compared to Otto cycle at the same operation condition. $\mathrm{NO}_{\mathrm{x}}$ emissions decreased up to $7.79 \%$ with MA cycle compared to Otto cycle due to the lower exhaust gas temperature at maximum brake torque engine speed of $2600 \mathrm{rpm}$. Keywords: Miller cycle, cam design, spline functions, engine performance, exhaust emissions
\end{abstract}

\section{Introduction}

Harmful exhaust emissions from internal combustion engines not only damage human health but also cause global warming. There are many studies carried out in the internal combustion engines to reduce fuel consumption and exhaust emissions [1-4,5]. Thermal efficiencies of Otto cycle engines are increased by increasing the compression ratio.
Supercharging also causes to increase indicated mean effective pressure and net cycle work. But these applications cause knocking and vibration in the engine. Thus, mechanical efficiency reduces. If the engine operates with lower charge mixture, in-cylinder gas temperature decreases. It causes the reduction on $\mathrm{NO}_{\mathrm{x}}$ and $\mathrm{CO}_{2}$ emissions. [2]. Thereby it has been aimed that engine can operate without knocking and 
reducing exhaust emissions and fuel consumption by modifying Otto cycle. In 1947, Ralph Miller first experimented Miller cycle $[4,6]$. In Otto cycle, compression and expansion ratios are the same. In Miller cycle, compression stroke is shortened according to expansion stroke. Network and efficiency could be increased by retarding the closing timing of intake valves [4,7]. Not only the fraction of charge mixture but also the temperature of the mixture is reduced by retarding the closing timing of the intake valves. Consequently, indicated mean effective pressure and net cyclic work are decreased. So, the most common method is supercharging and variable valve timing mechanism in order to increase cyclic work and efficiency in Miller cycle engine. LIVC causes to send back fresh charge to the intake manifold and the compression pressure decreases. But, the thermal efficiency increases by increasing the charge pressure with supercharging.

In the literature, there are many studies conducted on Miller cycle engines. Wu et al. [5] analyzed the performance of Otto cycle and supercharged Miller cycle. Zhao et al. [8] investigated the factors affecting the efficiency of a Miller cycle engine. They also determined the effects of compression ratio and air-fuel ratio on Miller cycle efficiency. Wang et al. [2] researched the variations of $\mathrm{NO}_{\mathrm{x}}$ emissions of a Miller cycle engine. They obtained that the $\mathrm{NO}_{\mathrm{x}}$ emissions of Miller cycle engine is lower compared to Otto cycle engine. Lin et al. [9] studied the effects of heat and frictional losses on air standard Miller cycle engine and compared to Otto cycle engine. They determined the reduction on network and power as heat and frictional losses increased. Mikalsen et al. [10] researched the potential advantages of the Miller cycle and compared to the Otto cycle. They also observed the improvement in fuel consumption compared to the Otto cycle.

Ebrahimi [11] performed the thermodynamic analysis of a standard Miller cycle. He determined that power decreased after a certain air-fuel ratio depending on compression ratio. Martins et al. [12] studied the effects of charge motion and different flow models on combustion in Miller cycle. They simulated Otto and Miller cycle by retarding of the closing timing of the intake valve $20^{\circ} \mathrm{CA}$. The minimum fuel consumption was obtained by LIVC timing. Okamoto et al. [13] investigated the effects of intake valve closing timing and EGR rate on engine performance and $\mathrm{NO}_{\mathrm{x}}$ emissions in a Miller cycle supercharged engine. They found that thermal efficiency is 38 $\%$ with LIVC timing and EGR. Tsukida et al. [14] attempted to raise the efficiency of Miller cycle. Furthermore, they reported that thermal efficiency is $36.1 \%$ by changing the intake valve lift and timing under stoichiometric operating conditions. In another study, Martins et al. [15] investigated the effects of variable valve timing and variable compression ratio on a Miller cycle. Simulations were performed using computer model in a single cylinder engine and they have obtained significant improvements with Miller cycle compared to Otto cycle. Lancefield et al. [16] investigated the effects of variable valve timing and different compression ratios on diesel engine performance. They also examined the effects of different valve lifts and valve timing variation on Miller and Atkinson cycles.

In this study, a new special camshaft was adapted to a single cylinder SI engine to perform LIVC Miller cycle by adjusting the intake valve closing timing. The detailed investigation was aimed to see the effects of LIVC Miller cycle on engine performance and exhaust emissions. For this reason, a new cam mechanism was adapted to the test engine and Miller cycle operation was performed with two different LIVC timing including $59.5^{\circ} \mathrm{CA}$ after $\mathrm{BDC}$ and $67^{\circ} \mathrm{CA}$ after $\mathrm{BDC}$. The valve timings were selected as $59.5^{\circ}$ $\mathrm{CA}$ after $\mathrm{BDC}$ and $67^{\circ} \mathrm{CA}$ after $\mathrm{BDC}$, because stable engine operation was provided with mentioned valve timings in Miller cycle. The variations of brake torque, power output, exhaust gas temperature, thermal efficiency, $\mathrm{SFC}, \mathrm{NO}_{\mathrm{x}}, \mathrm{CO}$ and $\mathrm{HC}$ emissions of the LIVC Miller and Otto cycle operations were investigated.

\section{Cam design}

A new special camshaft was designed and manufactured to operate the test engine with LIVC Miller cycle [17]. Valve lift, basic circle diameter and lifted valve period of the original cams were measured as $7 \mathrm{~mm}, 30 \mathrm{~mm}$ and $136^{\circ}$, respectively. By using these values, new cams were designed dependent on the $5^{\text {th }}$ order 
classical spline function. A classical spline of order $m$ is a curve made up of polynomial pieces that are blended together at their ends. The end points of the polynomial pieces are called knots. The curve is continuous and all of its derivatives are continuous, up to and including the derivative of order $\mathrm{m}-2$ [17-19]. The general expression of the $5^{\text {th }}$ order classical spline function is written as [17],

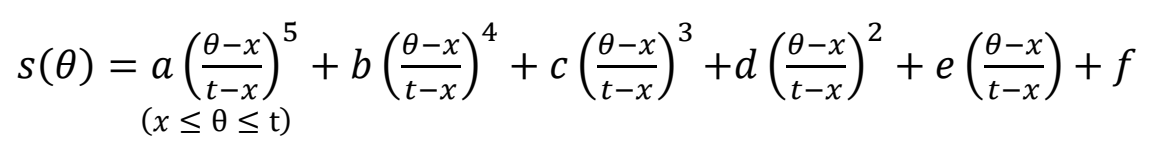

where $\theta$ is cam angle, $x$ and $t$ are start and end of the classical spline function depend on cam angle $[17,18]$.

Firstly, knot locations are determined using a classical spline. In order to satisfy the fundamental principle of cam design, knot locations and boundary conditions are defined, as shown in Table 1.

Four polynomials are joined together at three interior knots to get a smooth curve. The displacement equations of the above four polynomial pieces are [19, 20];

Table 1. Knot locations and boundary conditions

\begin{tabular}{lccccc}
\hline & \multicolumn{5}{c}{ Knot Locations (deg) } \\
\cline { 2 - 6 } Function & 0 & 34 & 68 & 102 & 136 \\
\hline Displacement & 0 & 3 & 7 & 3 & 0 \\
Velocity & 0 & - & - & - & 0 \\
Acceleration & 0 & - & - & - & 0 \\
\hline
\end{tabular}

$$
\begin{aligned}
& s_{1}(\theta)=a_{1}\left(\frac{\theta}{0.593}\right)^{5}+b_{1}\left(\frac{\theta}{0.593}\right)^{4}+c_{1}\left(\frac{\theta}{0.593}\right)^{3}+d_{1}\left(\frac{\theta}{0.593}\right)^{2}+e_{1}\left(\frac{\theta}{0.593}\right)+f_{1} \ldots \\
&(0 \leq\leq 0.593) \\
& s_{2}(\theta)= a_{2}\left(\frac{\theta-0.593}{0.593}\right)^{5}+b_{2}\left(\frac{\theta-0.593}{0.593}\right)^{4}+c_{2}\left(\frac{\theta-0.593}{0.593}\right)^{3}+d_{2}\left(\frac{\theta-0.593}{0.593}\right)^{2} \\
& \quad+e_{2}\left(\frac{\theta-0.593}{0.593}\right)+f_{2} \ldots
\end{aligned}
$$

$$
\begin{aligned}
s_{3}(\theta)= & a_{3}\left(\frac{\theta-1.186}{0.593}\right)^{5}+b_{3}\left(\frac{\theta-1.186}{0.593}\right)^{4}+c_{3}\left(\frac{\theta-1.186}{0.593}\right)^{3}+d_{3}\left(\frac{\theta-1.186}{0.593}\right)^{2} \\
& +e_{3}\left(\frac{\theta-1.186}{0.593}\right)+f_{3} \ldots \\
& (1.186 \leq \theta \leq 1.779)
\end{aligned}
$$

$$
\begin{aligned}
s_{4}(\theta)= & a_{4}\left(\frac{\theta-1.779}{0.593}\right)^{5}+b_{4}\left(\frac{\theta-1.779}{0.593}\right)^{4}+c_{4}\left(\frac{\theta-1.779}{0.593}\right)^{3}+d_{4}\left(\frac{\theta-1.779}{0.593}\right)^{2} \\
& +e_{4}\left(\frac{\theta-1.779}{0.593}\right)+f_{4} \ldots \\
& (1.779 \leq \theta \leq 2.374)
\end{aligned}
$$
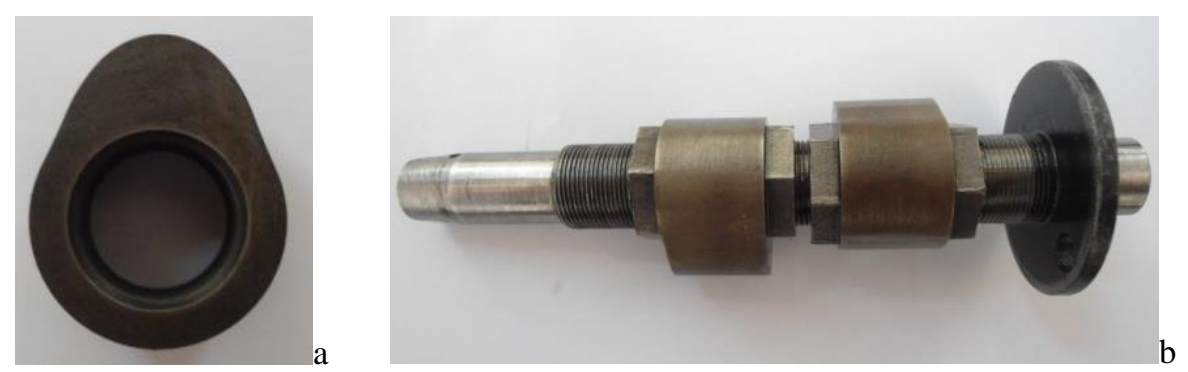

Figure 1. a) The new cam b) Adjustable camshaft mechanism

There are 24 unknown coefficients like $a_{1}, \ldots, a_{4}, b_{1}, \ldots, b_{4}, c_{1}, \ldots, c_{4}, d_{1}, \ldots, d_{4}$, $e_{1}, \ldots, e_{4}, f_{1}, \ldots, f_{4}$ requires 24 equations for solution. Successive derivations of the Eq. (2-5) give sets of equations for velocity, acceleration, jerk and ping. Fifteen smoothness equations, 
three interpolation equations, six boundary condition equations, a total of 24 equations are obtained as described in $[18,21,22,23]$. Displacement, velocity and acceleration curves of the designed cams were given by Cinar et. al. [17].

The cams were manufactured using the cam profile obtained by $5^{\text {th }}$ order classical spline method. The cams and their shaft were manufactured from SAE 4140 steel. The surfaces of the cams were hardened to $60 \mathrm{HRc}$. As seen in Figure 1, the inner surfaces of the cams and the outer surface of the shaft were screwed. Cams can be fixed by lock nuts on both sides when desired opening and closing timing are adjusted.

\section{Material and method}

\subsection{Test engine}

The experimental study was conducted in a single cylinder, four-stroke, SI engine. The technical specifications and the view of the test engine are given in Table 2 and Figure 2, respectively [23].

\begin{tabular}{|c|c|}
\hline Speciation & Description \\
\hline Model & LGA 340 \\
\hline Number of cylinder & 1 \\
\hline Cylinder bore $\mathrm{x}$ stroke $[\mathrm{mm}]$ & $82 \times 64$ \\
\hline Displacement [cc] & 338 \\
\hline Compression ratio & 8.5 \\
\hline Maximum power $[\mathrm{kW}]$ & $8.1 @ 3800$ rpm \\
\hline Maximum torque $[\mathrm{Nm}]$ & $23.7 @ 2600 \mathrm{rpm}$ \\
\hline Valve timing (Standard) IVO/IVC & $14^{\circ}$ before $\mathrm{TDC} / 52^{\circ}$ after BDC \\
\hline $\mathrm{EVO} / \mathrm{EVC}$ & $50^{\circ}$ before $\mathrm{BDC} / 14^{\circ}$ after $\mathrm{TDC}$ \\
\hline
\end{tabular}

Table 3. Technical specifications of Sun MGA 1500 type exhaust gas analyzer

\begin{tabular}{ccc}
\hline Parameter & Measuring range & Accuracy \\
\hline $\mathrm{CO}$ & $0-15 \%$ & $0.001 \%$ \\
$\mathrm{HC}$ & $0-9999 \mathrm{ppm}$ & $1 \mathrm{ppm}$ \\
$\mathrm{NO}_{\mathrm{x}}$ & $0-5000 \mathrm{ppm}$ & $1 \mathrm{ppm}$ \\
$\mathrm{CO}_{2}$ & $0-20 \%$ & $0.1 \%$ \\
$\mathrm{O}_{2}$ & $0-25 \%$ & $0.01 \%$ \\
Lambda & $0.6-1.2$ & 0.001 \\
\hline
\end{tabular}
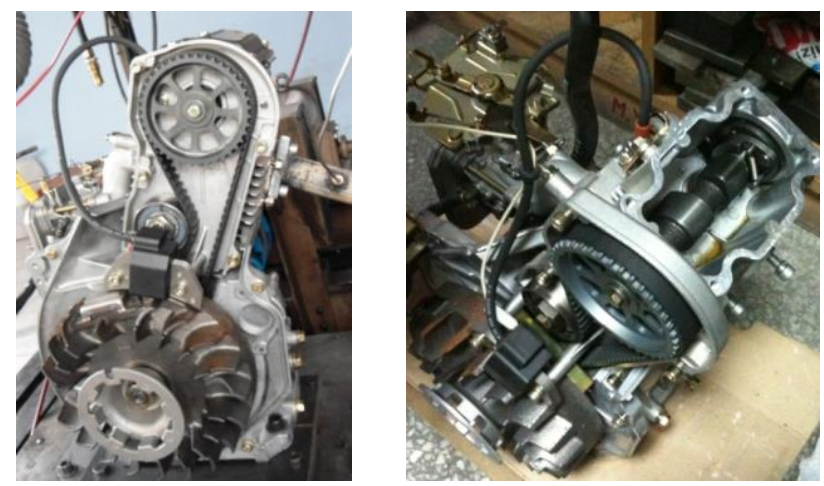

Figure 2. View of the test engine

\subsection{Experimental setup and testing procedure}

Experimental studies were carried out to determine the performance and emission characteristics of Otto and LIVC Miller cycles in a single cylinder SI engine. The experiments were performed at different engine speeds and WOT for both Otto and Miller cycles. The schematic view of the experimental setup is given in Figure 3. The test engine was fueled with unleaded gasoline.
The test engine was coupled with an electrical DC dynamometer on a Cussons P8160 type engine test bed. The dynamometer is rated for $10 \mathrm{~kW}$ at $4000 \mathrm{rpm}$. The engine load was measured with a strain gauge load cell sensor. Engine speed was measured with a magnetic pick-up sensor. A Sun MGA 1500 exhaust gas analyzer was used to measure $\mathrm{NO}_{\mathrm{x}}, \mathrm{CO}$ and $\mathrm{HC}$ emissions. The technical specifications of the exhaust gas analyzer are shown in Table 3. 


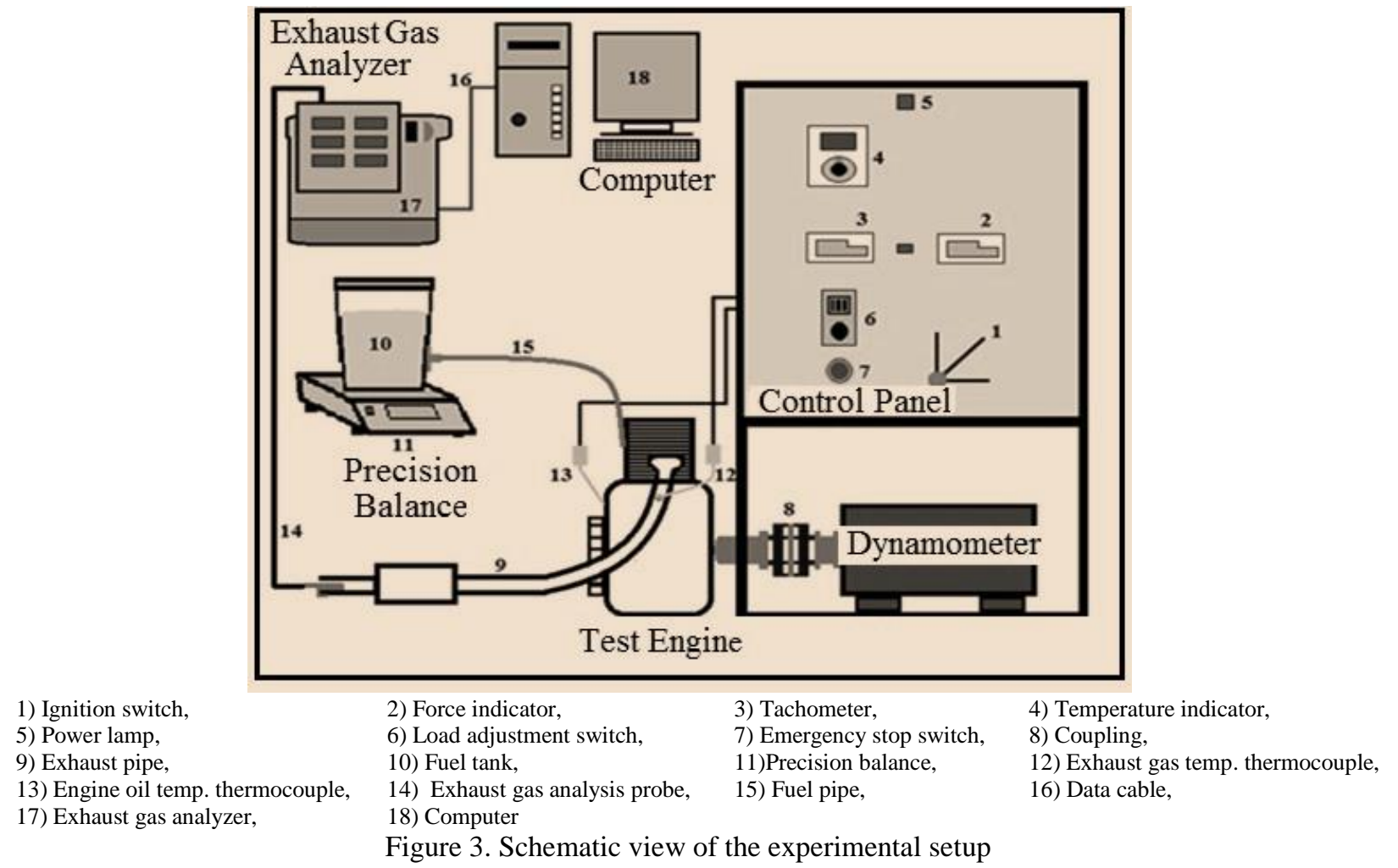

Table 4. The abbreviations and used different valve timings

\begin{tabular}{lll}
\hline \multicolumn{2}{c}{ Valve timings } & \multicolumn{1}{c}{ Abbreviations } \\
\hline IVC Timing & Standard (Table 2) & Otto cycle \\
IVC Timing & $59.5^{\circ} \mathrm{CA}$ after BDC & Miller Cycle (MA Cycle) \\
IVC Timing & $67^{\circ} \mathrm{CA}$ after BDC & Miller Cycle (MB Cycle) \\
\hline
\end{tabular}

The engine was tested between 1700-3200 rpm engine speed with the intervals of $300 \mathrm{rpm}$ at WOT. During the experiments, constant engine operating conditions were provided by keeping engine oil $80 \pm 3{ }^{\circ} \mathrm{C}$ temperature. Experiments were performed for a standard engine valve timing (Otto) and two different LIVC timing (MA and MB cycles). The abbreviations and used different valve timings are seen in Table 4. Valve closing timing is evident for Miller cycle. So, a new variable valve mechanism was manufactured and mounted to the test engine in the present study. At this point, classical spline method which is commonly used to obtain different cam profiles in internal combustion engines. A universal and practical different valve mechanism was produced and utilized for Miller cycle. Thus, the test engine was operated with Miller cycle. Then the effects of different LIVC timings with Miller cycle were observed on engine performance and exhaust emissions. As shown in Fig. 4, intake valve closing timing was retarded by 7.5 degrees crank angle (CA) intervals by adjustable camshaft mechanism for LIVC Miller cycle operation.
In the experiments, brake torque, output power, fuel consumption, $\mathrm{HC}, \mathrm{CO}, \mathrm{NO}_{\mathrm{x}}$ emissions and exhaust gas temperature were measured and calculated versus engine speed. The effects of LIVC timing were investigated on the performance and exhaust emissions.

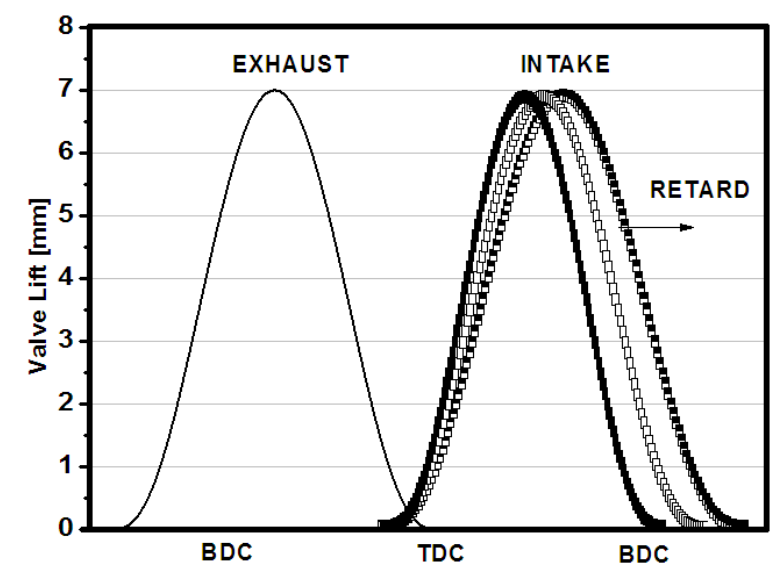

Figure 4. The variation of intake valve closing timing

\section{Result and Discussion}

Fig. 5 shows the brake torques versus engine speed for Otto, MA and MB cycles. Brake torque decreased after the $2600 \mathrm{rpm}$ due to the decrease of in-cylinder charge mixture and the 
increase of friction losses, for all cycles. Lower brake torque was obtained with MA and MB cycles comparing to Otto cycle [17]. The minimum brake torque was obtained with $\mathrm{MB}$ cycle especially at low engine speeds. A portion of mixture is discharged from the intake valves by LIVC because of low kinetic energy of the mixture for MB cycle at low engine speeds. On the other hand, lower engine speed allows discharging the mixture by LIVC timing, because there is sufficient time to discharge the mixture. So, charge mixture decreases in the cylinder with MB cycle. Consequently, brake torque decreases. Similarly, it can be stated that in-cylinder charge mixture decreased by LIVC timing for both Miller cycles at high engine speeds. Besides, the kinetic energy of the charge mixture in the cylinder also decreased dependent on engine speed. Later intake valve closing timing caused lower brake torque owing to lower compression ratio. Some fuel energy is also discharged from the intake line with LIVC timing. This phenomenon causes to deteriorate the oxidation reactions.

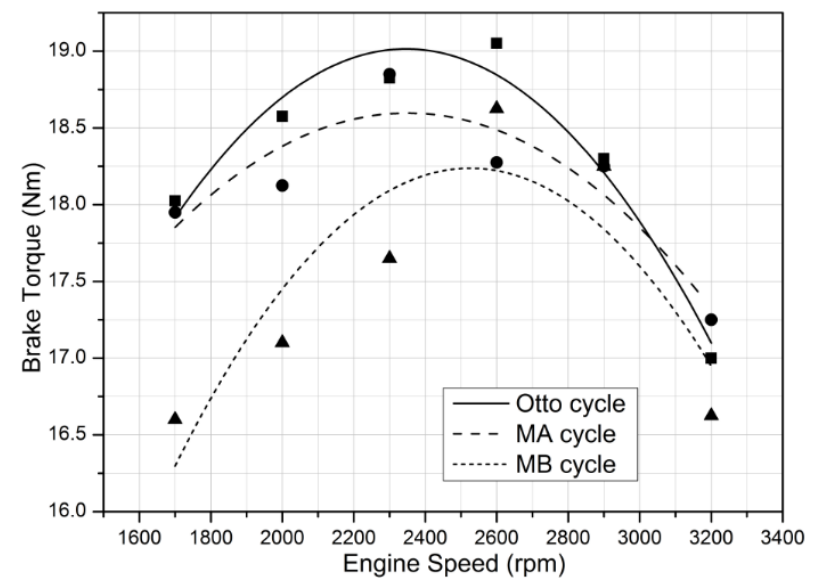

Figure 5. The variation of brake torques of three cycles versus engine speed

As shown in Fig. 6 power output increased with the increase of engine speed. At $1700 \mathrm{rpm}$ engine speed, power output was measured as $3.20 \mathrm{~kW}$ for Otto cycle, $3.19 \mathrm{~kW}$ for MA cycle and $2.77 \mathrm{~kW}$ for MB cycle. Similar results were obtained with experimental results $[17,23]$. The lowest power output was obtained with MB cycle, because a portion of charge mixture is discharged into the intake line resulting in lower air-fuel mixture at the end of intake process especially at lower engine speeds. Hence, charge mixture reduces per unit time in the cylinder. So, power output decreases. Maximum power output was obtained $5.69 \mathrm{~kW}$ at $3200 \mathrm{rpm}$ engine speed for Otto cycle. At the same engine speed, power output was $5.57 \mathrm{~kW}$ and $5.42 \mathrm{~kW}$ for MA cycle and MB cycle respectively. At $3200 \mathrm{rpm}$ engine speed, the power output increased by $2.15 \%$, with Otto cycle compared to MA cycle. The results showed that more power output is obtained for Otto cycle than Miller cycles for all engine speeds. It can be emphasized that Miller cycles have no advantages in view of power output.

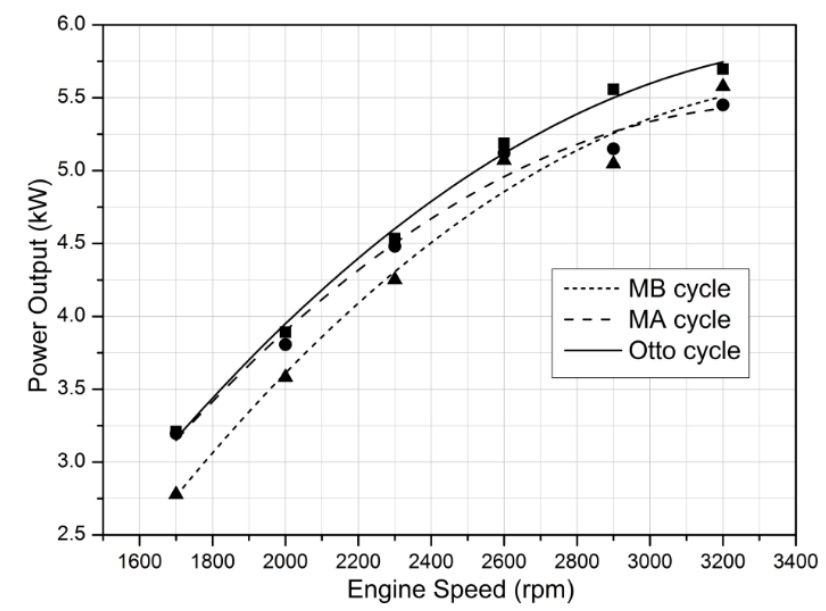

Figure 6. The variation of engine power output of three cycles

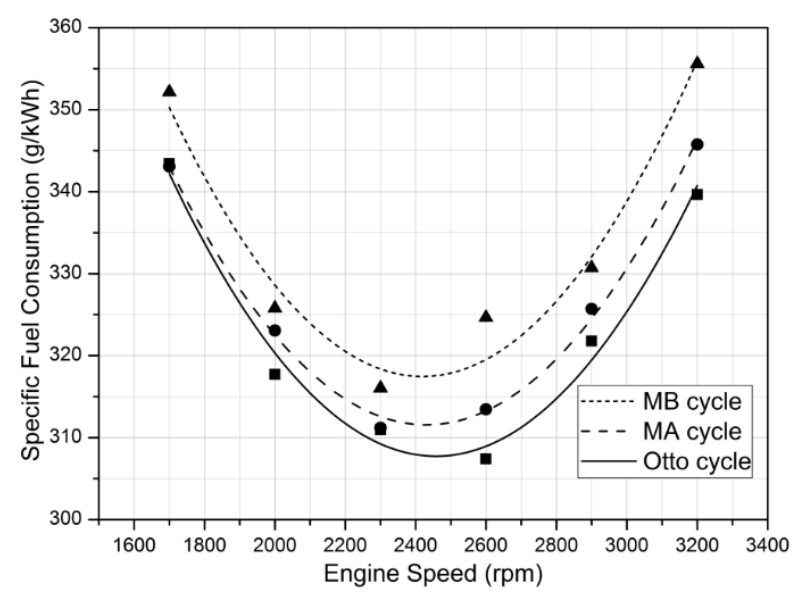

Figure 7. The variations of SFC for three cycles versus

SFC refers to consumed fuel per unit time for unit power output. The variations of SFC for three cycles versus engine speed were shown in Fig. 7. There is a good relationship between power output and SFC. The minimum SFC was obtained with Otto cycle. Some charge mixture and oxygen were discharged to the suction line due to LIVC timing. It could be deduced from Fig. 7 that SFC decreased since power output increased for Otto cycle compared to Miller cycles. Maximum SFC was obtained with MB cycle, because later intake valve closing timing 
caused to discharge more mixture into the suction line. The portion of mixture is discharged into the intake manifold by the piston. So the fuel consumption increases due to the wasted fuel. SFC decreased by about $2.08 \%$ with Otto cycle compared to MA cycle at maximum brake torque speed.

Exhaust gas temperature is related to in-cylinder combustion temperature and mixture composition. Fig. 8 demonstrated the variation of exhaust gas temperatures of three cycles. Exhaust gas temperature was measured $626^{\circ} \mathrm{C}$ at $1700 \mathrm{rpm}$ engine speed with Otto cycle. At the same engine speed exhaust gas temperature was measured $630{ }^{\circ} \mathrm{C}$ for MA cycle and $598^{\circ} \mathrm{C}$ for $\mathrm{MB}$ cycle. At $3200 \mathrm{rpm}$ engine speed exhaust gas temperature was $756^{\circ} \mathrm{C}$ for Otto cycle, 745 ${ }^{\circ} \mathrm{C}$ for MA cycle and $730{ }^{\circ} \mathrm{C}$ for $\mathrm{MB}$ cycle. It can be also concluded from Fig. 8 that incylinder charge mixture decreased owing to discharging into the suction line if the closing timing of the intake valves were delayed. Lower combustion temperature was obtained owing to lower charge mixture at the end of combustion. All charge mixture could not be trapped in the cylinder due to LIVC timing. Lower fuel energy is participated into the chemical oxidation reactions. It can be attributed that in-cylinder heat energy decreases due to loss of heat energy. This effect causes to decrease in-cylinder temperature and exhaust gas temperature.

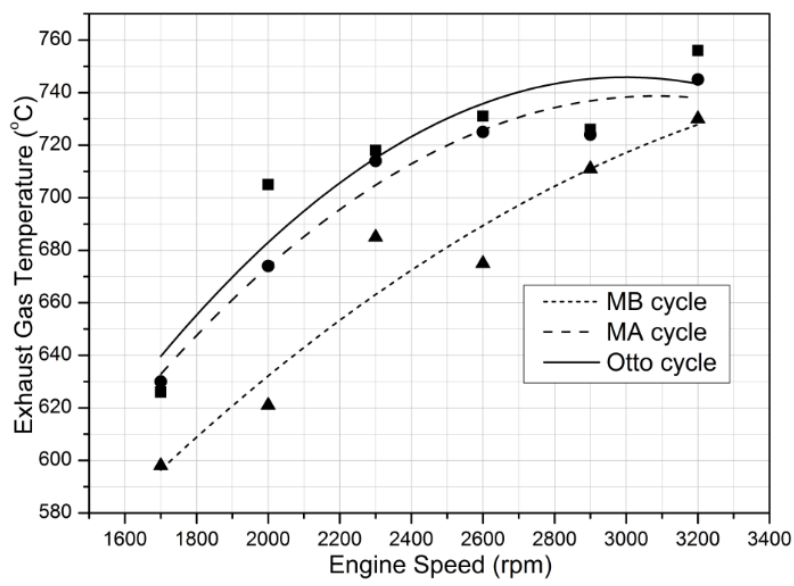

Figure 8 . The variation of exhaust gas temperature of three cycles

Fig. 9 shows the thermal efficiencies of three cycles. It can be found from figure 9 that Otto cycle is more efficient than Miller cycles especially at low and medium engine speeds. At $1700 \mathrm{rpm}$ engine speed, thermal efficiency of Otto cycle is $23.82 \%, 23.26 \%$ for MA cycle and
$23.23 \%$ for MB cycle. The maximum thermal efficiency was calculated as $26.51 \%$ with Otto cycle at $2600 \mathrm{rpm}$ engine speed. At this engine speed, thermal efficiency of MA cycle is $25.88 \%$ while the thermal efficiency of $\mathrm{MB}$ cycle is $25.85 \%$. At $3200 \mathrm{rpm}$ engine speed the thermal efficiency of Otto cycle is $24.08 \%$, MA cycle is $24.91 \%$ and MB cycle is $24.87 \%$. It can be depicted that thermal efficiency of Miller cycles are lower than Otto cycle due to lower power output. The reduction of the efficiency with Miller cycles are caused by the lower compression ratio, because compression ratio decreases with LIVC timing. Besides, a portion of mixture is sent back to the intake manifold by LIVC. So, it reduces the charge mixture in the cylinder at the end of intake stroke. Heat losses also increase by late closing of the intake valves with Miller cycle. The heat leakage losses cause to decrease the thermal efficiency. In other words, energy supplied to the cylinder decreases and then power output and thermal efficiency are seen to drop.

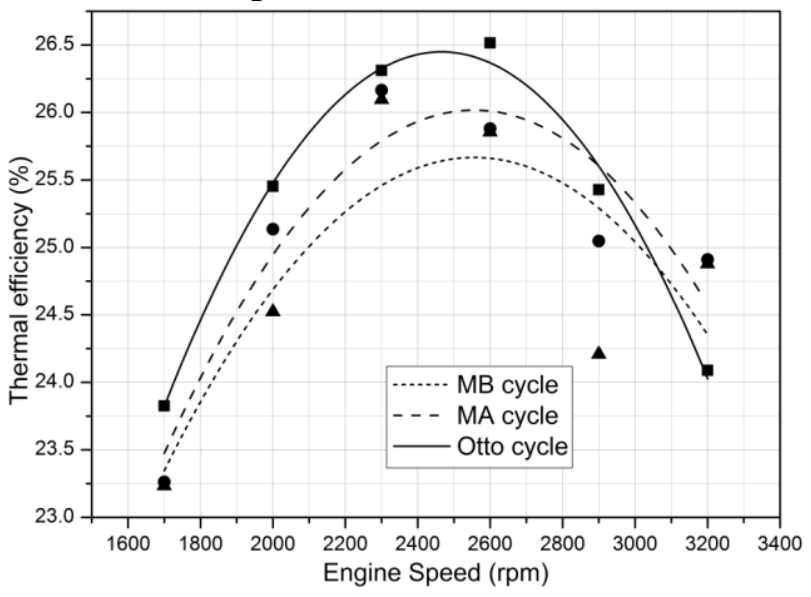

Figure 9. Calculated thermal efficiency of three cycles

The results of $\mathrm{NO}_{\mathrm{x}}$ emissions of three cycles versus engine speed are seen in Fig. 10. It is found from figure 10 that $\mathrm{NO}_{\mathrm{x}}$ emissions of three cycles increase with the increase of engine speeds for three cycles. It can be said that more charge mixture could be delivered to the cylinder and oxidation reactions improve due to tendency of turbulence and homogeneous charge mixture at high engine speeds. Nitrogen molecules are reacted with oxygen molecules at high combustion temperatures at the end of combustion. So, $\mathrm{NO}_{\mathrm{x}}$ emissions are produced. At $1700 \mathrm{rpm}$ engine speed $\mathrm{NO}_{\mathrm{x}}$ emission was measured 365 ppm for Otto cycle while 245 ppm for MA cycle and $155 \mathrm{ppm}$ for MB cycle at 
the same engine speed. $29.20 \%$ reduction was determined with $\mathrm{MB}$ cycle on $\mathrm{NO}_{\mathrm{x}}$ emissions according to Otto cycle at maximum brake torque speed. At $3200 \mathrm{rpm}$ engine speed $\mathrm{NO}_{\mathrm{x}}$ emissions were measured $950 \mathrm{ppm}$ for Otto cycle, $973 \mathrm{ppm}$ for MA cycle and $903 \mathrm{ppm}$ for $\mathrm{MB}$ cycle. It was shown that $\mathrm{NO}_{\mathrm{x}}$ emissions are always lower with Miller cycles compared to Otto cycle. The highest $\mathrm{NO}_{\mathrm{x}}$ emissions values were obtained with Otto cycle at all engine speeds. The main reason for the formation of $\mathrm{NO}_{\mathrm{x}}$ emissions in the combustion chamber is that exhaust gas temperature is too high at the end of the combustion. At the end of compression stroke, compression pressure and temperature can be decreased with Miller cycle compared to Otto cycle. For this reason, incylinder temperature decreases at the end of combustion and the mechanisms of $\mathrm{NO}_{\mathrm{x}}$ formation are slowed down compared to Otto cycle.

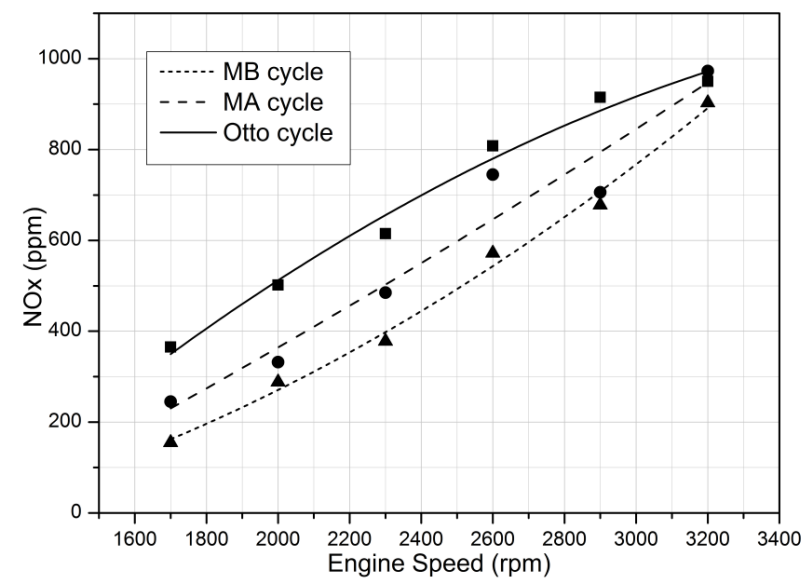

Figure 10. $\mathrm{NO}_{\mathrm{x}}$ emissions of three cycles

$\mathrm{CO}$ and $\mathrm{HC}$ emissions of three cycles versus engine speed are presented in Fig. 11. It can be concluded from Fig. 11-a that $\mathrm{CO}$ emissions decrease with the increase of engine speed for three cycles. $\mathrm{CO}$ is an incomplete combustion product due to lower oxygen concentration and insufficient temperature in the combustion chamber. $\mathrm{CO}$ reduces with the increase of engine speed due to higher air-fuel mixture and sufficient temperature. Volumetric efficiency decreases at high engine speeds and $\mathrm{CO}$ is generated. At $1700 \mathrm{rpm}$ engine speed $\mathrm{CO}$ emission was measured $1.36 \%$ for Otto cycle, $0.94 \%$ for MA cycle, $1.05 \%$ for MB cycle. At $3200 \mathrm{rpm}$ engine speed, $\mathrm{CO}$ emission was measured $0.82 \%$ for Otto cycle, $0.53 \%$ for MA cycle, $0.62 \%$ for $\mathrm{MB}$ cycle. It was seen that $\mathrm{CO}$ emissions first decreased with the increase of engine speed due to increase of combustion efficiency and then started to increase with the increase of engine speed due to deterioration of combustion. It can be mentioned that sufficient time is presented in order to take charge mixture into the cylinder due to LIVC timing and higher oxygen can be delivered to the cylinder resulting in lower CO. Furthermore, higher turbulence improved the oxidation reactions at higher engine speeds. So, CO reduced. The main reason for the formation of $\mathrm{CO}$ emissions is the lack of sufficient oxygen at the end of combustion reactions in the cylinder. If air and fuel are not homogenously mixed in the cylinder, incomplete combustion is seen. Hence, $\mathrm{CO}$ emissions increase due to deterioration of combustion. Fig. 11-b shows the results of HC emissions of three cycles versus engine speed.
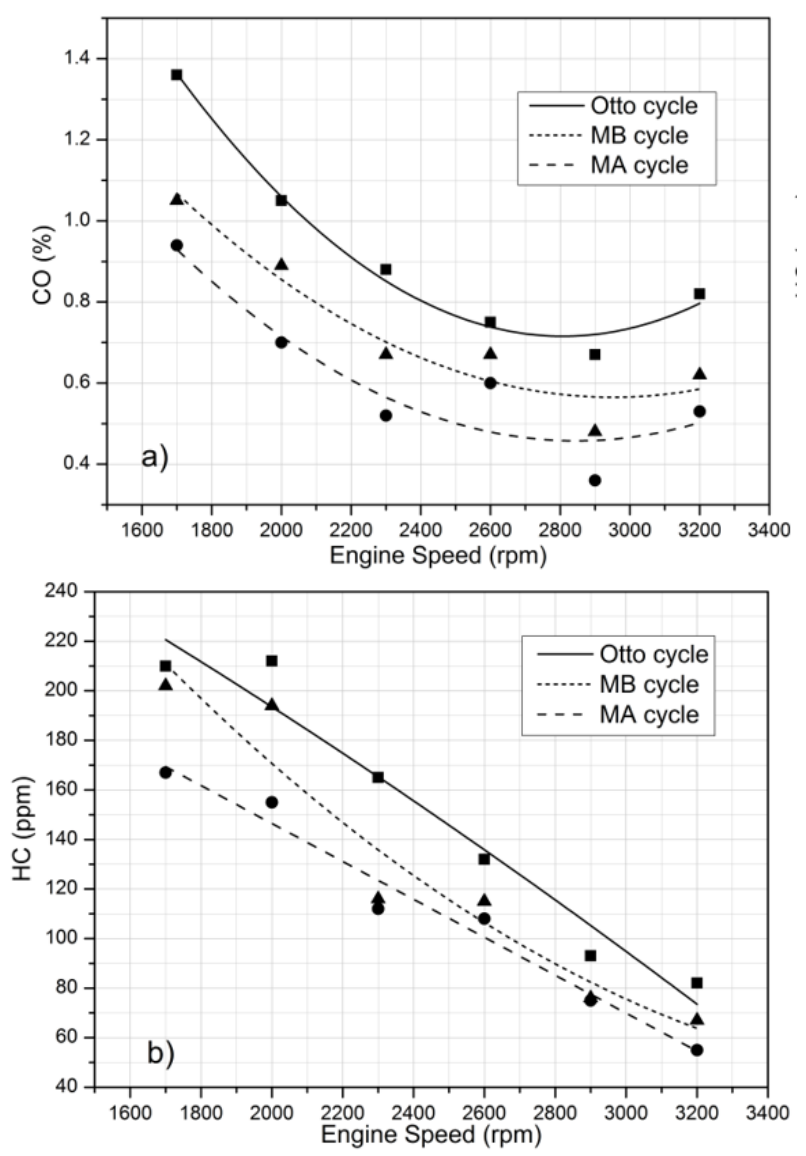

Figure 11. $\mathrm{CO}$ and $\mathrm{HC}$ emissions of three cycles

Similar trend was seen on HC emissions. HC emissions decreased with the increase of engine speed for Otto and Miller cycles. At $1700 \mathrm{rpm}$ engine speed, $\mathrm{HC}$ emission was measured 210 ppm for Otto cycle, 167 ppm for MA cycle and $202 \mathrm{ppm}$ for MB cycle. At $3200 \mathrm{rpm}$ engine speed, HC emission was measured $82 \mathrm{ppm}$ for 
Otto cycle, 55 ppm for MA cycle and $67 \mathrm{ppm}$ for MB cycle. The combustion duration decreases with the increase of engine speed, but in-cylinder temperature increases. This increase improves the combustion reactions and reduces the $\mathrm{HC}$ emissions.

\section{Conclusions}

This study focuses on the benefits of intake valve closing timing with Miller cycle performance. The results showed that brake torque decreased owing to decrease of mixture in the cylinder and the friction losses after 2600 rpm engine speed for three cycles. The kinetic energy of mixture increased with the increase of engine speed and brake torque started to increase. Lower brake torque was obtained with MB cycle because of low kinetic energy and the amount of the mixtures at low engine speeds. Besides more power output was obtained with Otto cycle than Miller cycles especially at low and medium speeds. According to the test results, brake torque and engine power decreased by $4.24 \%$, and $1.30 \%$ respectively with MA cycle compared to Otto cycle at 2600 rpm engine speed. Thermal efficiency increased by $1.29 \%$, while the SFC decreased $2.08 \%$ with Otto cycle according to MA cycle at maximum brake torque speed. The most significant effects were seen with Miller cycles are seen on emissions. $\mathrm{HC}$ and $\mathrm{CO}$ decreased by $6.48 \%$ and $11.66 \%$ respectively with MA cycle compared to Otto cycle at the same operation condition. $\mathrm{NO}_{\mathrm{x}}$ emissions decreased up to $7.79 \%$ with MA cycle compared to Otto cycle due to the lower exhaust gas temperature at maximum brake torque speed of $2600 \mathrm{rpm}$. The test results also showed that the SFC increased since power output decreased for MB cycle at low and medium engine speeds. The SFC for MB cycle was much than Otto cycle due to the wasted fuel by LIVC timing. Exhaust gas temperature for Miller cycles were less than Otto cycle at all engine speeds. For this reason, up to $7 \%$ decrease was observed in $\mathrm{NO}_{\mathrm{x}}$ emissions due to the lower exhaust gas temperature at Miller cycle conditions compared to Otto cycle. Furthermore, the thermal efficiencies of Miller cycles are lower than Otto cycle due to lower power output. For all cycles, $\mathrm{CO}$ emissions first decreased with the increase of engine speed and then started to increase with the increase of engine speed due to deterioration of combustion. Similarly, HC emissions decreased with the increase of engine speed. According to test results, it can be said that Otto cycle is the best operation condition in view of engine performance while Miller cycles are better in view of exhaust emissions. Miller cycle engine performance could be improved by turbocharging and variable valve timing systems. Further experimental studies can be carried out to observe the heat leakage loss, frictional losses and vibration in a detail with Miller cycle.

\section{References}

1. Wang, Y., Lin, L., Zeng, S., Huang, J., Roskilly, A.P., He, Y., Huang, X., Li, S., Application of the Miller cycle to reduce NOx emissions from petrol engines. Applied Energy, 2008; 85(6), 463-474.

2. Wang, Y., Lin, L., Roskilly, A.P., Zeng, S., Huang, J., He, Y., Huang, X., Huang, H., Wei, H., Li, S., Yang, J. An analytic study of applying Miller cycle to reduce NOx emission from petrol engine. Applied Thermal Engineering, 2007; 27(11-12), 1779-1789.

3. Ge, Y., Chen, L., Sun, F., Wu, C., Effects of heat transfer and friction on the performance of an irreversible air-standard Miller cycle. International Communications in Heat and Mass Transfer, 2005; 32(8), 1045-1056.

4. Miller, R.H., Supercharging and internal cooling cycle for high output. Trans ASME, 1947; 69, 453-464.

5. Wu, C., Puzinauskas, P.V., Tsai, J.S., Performance analysis and optimization of a supercharged Miller cycle Otto engine. Applied Thermal Engineering, 2003; 23(5), 511-521.

6. Miller, R.H., Lieberherr, H.U., The Miller supercharging system for Diesel and gas engines operating characteristics, CIMAC, 1957. In: Proceedings of the 4th International Congress on Combustion Engines, Zurich. June 1957; 1522, 787-803.

7. Simmons, L.D. Altering the spark-ignited internal combustion engine cycle, thermodynamics and the design, analysis, and improvement of energy systems, ASME AES, 1994; 33, 205-210.

8. Zhao, Y., Chen, j., Performance analysis of an irreversible miller heat engine and its 
optimum criteria. Applied Thermal Engineering, 2007; 27(11-12), 2051-2058.

9. Lin, J.C., Hou, S.S. Performance analysis of an air-standard Miller cycle with considerations of heat loss as a percentage of fuel's energy, friction and variable specific heats of working fluid. International Journal of Thermal Sciences, 2008; 47(2), 182-191.

10. Mikalsen, R., Wang, Y.D., Roskilly, A.P. A comparison of Miller and Otto cycle natural gas engines for small scale CHP applications. Applied Energy, 2009; 86(6), 922-927.

11. Ebrahimi, R., Performance analysis of an irreversible Miller cycle with considerations of relative air-fuel ratio and stroke length. Applied Mathematical Modelling, 2012; 36(9), 40734079.

12. J. Martins, J. Ribeiro, S. Teixeira, Incylinder swirl analysis of different strategies on over-expanded cycles. 20 $0^{\text {th }}$ International Congress of Mechanical Engineering, 2009.

13. Okamoto, K., Zhang, F.R., Shimogata, S., Shoji, F., Development of a late intake valve closing (LIVC) Miller cycle for stationary natural gas engines- effect of EGR utilization, Society of Automotive Engineers Inc., 1997; 972948, 87-99.

14. Tsukida, N., Sakakura, A., Murata, Y., Okamoto, K., Takemoto, T., Development of Miller cycle gas engine for cogeneration. Proceeding of the ASME Advanced Energy Systems Division, 1999;453-457.

15. Ribeiro, B., Martins, J., Direct comparison of an engine working under Otto, Miller and Diesel cycles: thermodynamic analysis and real engine performance. SAE Paper 2007-01-0261, 2007.

16. Lancefield, T., Methley, I., Rase, U., Kuhn, T., The application of variable event valve timing to a modern diesel engine. SAE Paper, 2000-01-1229, 2000.

17. Cinar, C., Sahin, F., Can, Ö., Uyumaz, A., A comparison of performance and exhaust emissions with different valve lift profiles between gasoline and LPG fuels in a SI engine, Applied Thermal Engineering, 2016; 107, 12611268.

18. Hsieh, J. F., Design and analysis of cams with three circular-arc profiles. Mechanism and Machine Theory, 2010; 45(6), 955-965.

19. Norton, R. L., Cam design and manufacturing handbook, 67, Industrial Press
Inc., 10016-4078, United States of America, 2002.

20. Nguyen, V.T., Kim, D.J., Flexible cam profile synthesis method using smoothing spline curves. Mechanism and Machine Theory, 2007; 42(7), 825-838.

21. Mandal, M., Naskar, T.K., Introduction of control points in splines for synthesis of optimized cam motion program. Mechanism and Machine Theory, 2009; 44(1), 255-271.

22. Karabulut, H., Sarıdemir, S., Comparison of cam profiles obtained via classical spline method for different lifted-valve periods and lifts. Journal of the Faculty of Engineering and Architecture of Gazi University, 2009; 24(3), 509-515.

23. Demirci, O.K., Application of Miller Cycle in a Spark Ignition Engine and the Investigation of Performance and Emission Characteristics, M.Sc. Thesis, Gazi University Institute of Science and Technology, 2013.

24. Eyidogan, M., Özsezen, A.N., Canakci, M., Turkcan, A., Impact of alcohol-gasoline fuel blends on the performance and combustion characteristics of an SI engine. Fuel, 2010; 89(10), 2713-2720. 